\title{
TURISMO E LITERATURA: ANÁLISES A PARTIR DAS LENTES DAS MOBILIDADES
}

\section{TOURISM AND LITERATURE THROUGH THE LENS OF MOBILITIES \\ TURISMO Y LITERATURA MEDIANTE DE LAS LENTES DE LAS MOVILIDADES}

\author{
Carla Fraga ${ }^{1}$ \\ Universidade Federal do Estado do Rio de Janeiro, Rio de Janeiro, Brasil \\ Maria Jaqueline Elicher ${ }^{2}$ \\ Universidade Federal do Estado do Rio de Janeiro, Rio de Janeiro, Brasil \\ Camila Maria dos Santos Moraes ${ }^{3}$ \\ Universidade Federal do Estado do Rio de Janeiro, Rio de Janeiro, Brasil
}

\begin{abstract}
Resumo: Este artigo apresenta uma análise da relação entre Turismo e Literatura a partir de uma visão multidisciplinar. $\mathrm{O}$ estudo se caracteriza como exploratório e descritivo, partindo de um levantamento bibliográfico. O corpus foi analisado quanto à: distribuição dos resumos por ano de publicação; áreas geográficas de interesse; conteúdo textual dos resumos. Os resultados evidenciam a importância do estudo da interface em si e de como esses dois universos se entrelaçam e se mobilizam, sendo a cidade um ambiente relevante para a ocorrência desta relação.
\end{abstract}

Palavras-chave: Turismo; Literatura; Mobilidades.

\begin{abstract}
From the multidisciplinary point of view, the aim of this paper was to analyze the relationship between tourism and literature. This exploratory and descriptive study was realized from the bibliographic review, was analyzed by: distribution of abstracts per year of publication; interest geographical areas; textual content of abstracts. The result shows the relevance of the interface study itself and how tourism and literature entwined and mobilize with each other, being the city a consistent ambient to the occurrence of this relationship.
\end{abstract}

Keywords: Tourism; Literature; Mobilities.

\footnotetext{
${ }^{1}$ Departamento de Turismo e Patrimônio da Universidade Federal do Estado do Rio de Janeiro (UNIRIO), Professora Associada, carla.fraga@unirio.br

${ }^{2}$ Departamento de Turismo e Patrimônio da Universidade Federal do Estado do Rio de Janeiro (UNIRIO), Professora Adjunta, maria.elicher@unirio.br

${ }^{3}$ Departamento de Turismo e Patrimônio da Universidade Federal do Estado do Rio de Janeiro (UNIRIO), Professora Adjunta, camila.moraes@unirio.br
} 
Resumen: Este artículo presenta un análisis de la relación entre Turismo y Literatura desde una visión multidisciplinaria. El estudio se caracteriza por ser exploratorio y descriptivo, basado en una encuesta bibliográfica, analizándose en cuanto a: distribución de resúmenes por año de publicación; áreas geográficas de interés; contenido textual de los resúmenes. Los resultados muestran la importancia de estudiar la interfaz en sí y cómo estos dos universos se entrelazan y movilizan, siendo la ciudad un entorno relevante para la ocurrencia de esta relación.

Palabras clave: Turismo; Literatura; Movilidades.

\section{INTRODUÇÃO}

as viagens das pessoas e das coisas, das imagens e das ideias estão sempre, de maneira direta ou indireta, interligadas em sistemas cada vez mais complexos e interdependentes (...) (FREIRE-MEDEIROS; PINHO, 2016, p.5).

Turismo faz parte do universo amplo das viagens, e portanto das mobilidades, e nesse sentido o próprio Paradigma das Novas Mobilidades (PNM) de Sheller e Urry (2006), como uma visão multidisciplinar, torna-se relevante para se analisar a interface entre Turismo e Literatura, inclusive do ponto de vista epistemológico.

Por outro lado, a análise da evolução de número de publicações por ano, bem como a análise da distribuição geográfica das áreas de interesse dos estudos, e do conteúdo textual destes, a partir da produção científica, pode evidenciar, mesmo que em parte, como a construção epistemológica sobre Turismo e Literatura está ocorrendo. Portanto, o objetivo geral deste estudo foi analisar a interface entre Turismo e Literatura com base na produção científica em Turismo. Já os objetivos específicos foram: (a) identificar aspectos específicos da interface entre Turismo e Literatura; (b) compreender a visão multidisciplinar, a partir do emprego do Paradigma das Novas Mobilidades (PNM).

Esse estudo é exploratório e descritivo, foi realizado a partir de levantamento bibliográfico através de consulta ao website Publicações de Turismo ${ }^{4}$, sendo que o artigo

\footnotetext{
${ }^{4}$ Publicações de Turismo é um projeto de extensão do Programa de Pós-Graduação em Turismo da EACHUSP desenvolvido pelo Professor Glauber Santos. Disponível no endereço eletrônico: <http://www.each.usp.br/turismo/publicacoesdeturismo/>.
} 
está subdividido em quatro partes além desta Introdução e das Considerações Finais. A próxima seção aborda a interface Turismo e Literatura (seção 1). Já a seção 2 aborda o PNM, a seção 3 apresenta a metodologia e na seção 4 são apresentados e discutidos os resultados.

\section{TURISMO E LITERATURA}

Na literatura é notório a importância da espacialidade e dos deslocamentos. Estudar a intersecção do turismo com a literatura implica, portanto, compreender os movimentos espaciais, seja entre destinos ou intradestinos. Como afirma Simões (2009) essa compreensão e, sobretudo, a do funcionamento do mercado cultural globalizado, é extremamente necessária, pois é a forma de valorização do discurso literário e do bem simbólico local que habita sobremaneira o imaginário ficcional.

O entendimento de uma literatura de turismo ou um turismo literário, por sua vez, caminha na perspectiva de Hendrix (2007) apud Quinteiro e Baleiro (2014), para quem a literatura de turismo refere-se àqueles textos que apresentam referências explícitas às práticas turísticas e que encerram representações do espaço que adquirem o valor de atrações turísticas. Nesse sentido, a literatura de turismo designa os textos literários que têm o condão de motivar leitores a transformarem-se em 'turistas de fato', e a realizar viagens para além daquelas que os livros proporcionam, de modo a sentirem-se mais próximos dos livros, dos autores e dos personagens. Ou seja, estes textos conseguem promover o turismo literário que tem a especificidade de implicar o deslocamento (real ou virtual) a lugares, de algum modo, relacionado com a literatura.

Assim, a literatura de turismo designa um conjunto de textos que são passíveis de interdisciplinaridade nas áreas da literatura e do turismo e não se trata apenas dos textos literários cuja autoria ou representações literárias atribuem valor turístico a um dado local, mas também, como se refere Hendrix (2007) apud Quinteiro e Baleiro (2014) àqueles que promovem a reflexão sobre o turismo e as atividades turísticas e retratam práticas do turismo, a partir da viagem, independente da distância percorrida e, de fazê-la ou não, buscando o alargamento do olhar do espaço do outro naquele espaço. 
Nesta direção, para além de uma mera 'turistificação literária', a visita literária pode ampliar o olhar do visitante sobre os novos espaços e contribuir para uma valorização do cotidiano e todas as formas de representações coletivas traduzidas pela literatura, que embora sejam aspectos que surjam despidos de uma linguagem científica, podem ir além, exercendo a subjetividade imaginativa, remetendo ao imaginário do leitor e promovendo como desdobramentos da viagem, novas leituras sobre o espaço e possibilidades de alargamento de si mesmo e o pensar nas diferenças que forjam este espaço. As experiências do turismo literário não são, portanto, vivências sem bagagem, pois o viajante vem carregado de imaginários dos diferentes lugares e, que conforme Massey (2008), geram identificações que são forjadoras de novas formas de ver e sentir.

O turismo se realiza no espaço, uma espacialidade que reflete as práticas turísticas, portanto. Nesta perspectiva o deslocamento, ou a viagem, implica no desejo do viajante ou, do turista, em recusar, conforme Onfray (2009, p. 08) os clichês pré-estabelecidos e "instrumentos comparativos que imponham a leitura de um lugar com os referenciais de um outro", o que se subentende um "deixar-se preencher pelo líquido local, 'a maneira dos vasos comunicantes',".

Ainda segundo Onfray (2009, p.11) cada um de nós se descobre nômade ou sedentário, "amante de fluxos, transportes, deslocamentos, ou apaixonado por estatismo, imobilismo e raízes". Mesmo que cada um de nós esteja limitado em suas possibilidades de viajar, seja por ausência de recursos ou dificuldades para entrar num país ou outras contingências, e são múltiplas as contingências no mundo atual, são raros aqueles que podem e conseguem se desatrelar por completo "de sua rigidez de árvore pra virar correnteza do rio" (ONFRAY, 2009, p. 23). O deslocamento no tempo e no espaço é, portanto, a possibilidade de construção de si mesmo e a ressignificação do seu modo de ver o mundo e de senti-lo, é o se perder na viagem e no 'olhar pela janela'. Na próxima seção será abordado o Paradigma das Novas Mobilidades (PNM) como um aporte teórico e metodológico relevante para os estudos desta interface.

\section{PARADIGMA DAS NOVAS MOBILIDADES}


Carla Fraga

Maria Jaqueline Elicher

Camila Maria dos Santos Moraes
Geografia, Literatura e Arte, v.2, n.2, p. 90-108, jul./dez.2020

DOI: 10.11606/issn.2594-9632.geoliterart.2020.170156

Para a melhor compreensão e análise dos dados apresentados neste artigo, recorreuse ao Paradigma das Novas Mobilidades (PNM). Elaborado, inicialmente, pelos sociólogos Mimi Sheller e John Urry no começo dos anos 2000 (SHELLER; URRY, 2004), o PNM tem sido construído por pesquisadores de diferentes disciplinas e localizados em várias partes do globo (MORAES, 2017).

Para Urry, na virada do milênio, assistimos a uma intensificação de fluxos demandando, assim, uma nova forma de se pensar as sociedades. Considerando que as mobilidades são um fenômeno social complexo que vai além das dimensões físicas, corporais e econômicas, tradicionalmente analisadas em estudos sobre viagens, transportes, mobilidade social, o sociólogo propõe o reposicionamento das mobilidades como uma importante lente de análise (URRY, 2000; URRY, 2007; MORAES, 2017).

Na introdução à coletânea Tourism mobilities: places to play places in play (2004), Sheller e Urry analisam o turismo sob as lentes das mobilidades, o que chamam de mobilidades turísticas. Para isso, avaliam como a compressão tempo - espaço, resultado de inovações e ampliação de acesso a diferentes meios de transporte, com novas tecnologias de informação e comunicação, trouxeram as pessoas em todo o mundo para mais perto umas das outras, aumentando os fluxos de viajantes, migrantes e turistas que se deslocam de um lugar para o outro e produzem novos lugares turísticos (SHELLER; URRY, 2004, p.3-4, apud MORAES, 2017).

Para compreender a proposta dos sociólogos, é importante lembrar que lugares são construídos por pessoas e suas práticas sociais, culturais, políticas e econômicas no espaço. São, portanto, produzidos a partir da mobilidade, encontros, contatos e rede de capitais, pessoas, objetos, sinais e informações, do que Santos (1997) definiu como a reflexão de nossa relação com o mundo. O lugar (e porque não, o lugar turístico) constitui, portanto, a dimensão da existência que se manifesta através de um cotidiano compartido entre as mais diversas pessoas, firmas e instituições-cooperação, que são, na verdade, a base da vida em comum (SANTOS, 1997). Disto isto, Sheller e Urry (2004) propõem os estudos sobre os lugares 
turísticos a partir dos movimentos dos complexos sistemas formados pela combinação de redes de pessoas e lugares (MORAES, 2017).

Esta é a ideia que perpassa a noção de "places to play / places in play" - lugares para jogo ou lugares para performance. Considerando que play em inglês também significa peça teatral, ou espaço para performance, os lugares são, assim, performados ou elaborados por diversos atores, sejam esses residentes, operadoras de turismo, ONGs, Estado e turistas. Por isso, não faz sentido olhar para o turista em separado do lugar, ou para o lugar separado dos turistas, mas, sim, olhar para os movimentos e redes que se formam nestes lugares, tornandoos turísticos (MORAES, 2017).

Assim, o Paradigma das Novas Mobilidades abre uma nova perspectiva para estudos de turismo. Isto porque oferece uma fuga das tradicionais dicotomias, tais como as análises sobre as motivações dos turistas ou dos impactos aos ambientes físicos e/ou culturais, e passa a oferecer um olhar e um entendimento sobre as mobilidades estruturantes do turismo como um sistema híbrido e complexo composto por objetos, lugares, tecnologias e relações sociais (MAVRIC; URRY, 2009; MORAES, 2017). Dito isto, a “turistificação literária" abordada neste artigo, analisa como os lugares se movem ou viajam também através dos textos literários. Ou seja, a circulação de imagens, significados, objetos e corpos responsáveis por criar e mobilizar lugares através de textos literários tornam-se um criativo objeto de análise.

\section{METODOLOGIA}

Como mencionado na Introdução, o estudo é exploratório e descritivo, foi realizado a partir de levantamento bibliográfico. Este levantamento foi realizado a partir do website Publicações de Turismo, que reúne 40 periódicos científicos iberoamericanos de Turismo com 11.139 artigos indexados. Nesta primeira etapa, foi possível identificar 40 artigos que apresentavam no título a palavra 'Literatura', dos quais nove resumos $(n=9)$ estavam em português, e se relacionam a esta, enquanto um objeto e não enquanto aspectos metodológicos empregados, tal como 'revisão da literatura' para um determinado objeto de pesquisa. Assim não foram considerados: Antelmi e Santulli (2012), pois o resumo não estava 
Carla Fraga

Maria Jaqueline Elicher

Camila Maria dos Santos Moraes
Geografia, Literatura e Arte, v.2, n.2, p. 90-108, jul./dez.2020

DOI: 10.11606/issn.2594-9632.geoliterart.2020.170156

em português; Tejero (2017), por se tratar de um resumo expandido, Quinteiro (2019), por se tratar de uma 'Introdução'.

Numa segunda etapa, o material selecionado foi codificado e analisado quanto: (a) a distribuição dos resumos por ano de publicação através de gráfico elaborado a partir de planilha do Excel; (b) as áreas geográficas de interesse, gerando um mapa através do software QGis 3.8 Zanzibar; (c) ao conteúdo textual dos resumos através do software Iramuteq (versão 0.7 alpha 2) gerando análise estatística textual, a análise de similitude e a nuvem de palavras. Este é um software open source e utiliza o software estatístico R para elaborar análises do corpus textual (SALVIATI, 2017).

O Quadro 1 apresenta o passo metodológico da codificação que compõem o banco de dados para a formação do corpus textual baseado nos resumos dos artigos:

Quadro 1. Codificação dos Resumos

\begin{tabular}{|c|c|c|c|c|}
\hline Codificação* & Título & $\begin{array}{c}\text { Palavras- } \\
\text { Chave }\end{array}$ & $\begin{array}{l}\text { Autor (es) } \\
\quad \text { (ano) }\end{array}$ & Períódico \\
\hline $\begin{array}{c}* * * * * \\
\text { Resumo_1 }\end{array}$ & $\begin{array}{l}\text { Os doces e licores artesanais } \\
\text { da literatura sul-baiana e sua } \\
\text { relação com o turismo à luz } \\
\text { das indústrias criativas }\end{array}$ & $\begin{array}{l}\text { Cultura; Turismo; } \\
\text { Economia } \\
\text { Criativa. }\end{array}$ & $\begin{array}{l}\text { Costa } \\
(2008)\end{array}$ & $\begin{array}{c}\text { Caderno Virtual do } \\
\text { Turismo }\end{array}$ \\
\hline $\begin{array}{c}* * * * * \\
\text { Resumo_2 }\end{array}$ & $\begin{array}{l}\text { Os paradoxos do acolhimento } \\
\text { em Minas no século XIX de } \\
\text { acordo com a literatura de } \\
\text { viagem: hospitalidade e } \\
\text { hostilidade }\end{array}$ & $\begin{array}{l}\text { Acolhimento; } \\
\text { Viajantes } \\
\text { Naturalistas; } \\
\text { Minas Gerais; } \\
\text { Hospitalidade; } \\
\text { Hostilidade. }\end{array}$ & $\begin{array}{l}\text { Brusadin } \\
(2018)\end{array}$ & $\begin{array}{c}\text { Caderno Virtual do } \\
\text { Turismo }\end{array}$ \\
\hline $\begin{array}{c}* * * * * \\
\text { Resumo_3 }\end{array}$ & $\begin{array}{l}\text { Turismo, Arqueologia e } \\
\text { Literatura: análise } \\
\text { antropológica da construção } \\
\text { da memória coletiva em São } \\
\text { Nicolau, Rio Grande do Sul }\end{array}$ & $\begin{array}{l}\text { Turismo; } \\
\text { Missões; } \\
\text { Memória; } \\
\text { História; } \\
\text { Arqueologia; } \\
\text { Literatura. }\end{array}$ & $\begin{array}{l}\text { Brum } \\
(2007)\end{array}$ & $\begin{array}{l}\text { Revista Brasileira } \\
\text { de Pesquisa em } \\
\text { Turismo }\end{array}$ \\
\hline
\end{tabular}


Carla Fraga

Maria Jaqueline Elicher

Camila Maria dos Santos Moraes
Geografia, Literatura e Arte, v.2, n.2, p. 90-108, jul./dez.2020

DOI: 10.11606/issn.2594-9632.geoliterart.2020.170156

\begin{tabular}{|c|c|c|c|c|}
\hline $\begin{array}{c}* * * * * \\
\text { Resumo_4 }\end{array}$ & $\begin{array}{c}\text { Acolher, explicar, desvelar: } \\
\text { até onde me apresentar ao } \\
\text { outro? Transparência e } \\
\text { opacidade nas literaturas } \\
\text { francófonas }\end{array}$ & $\begin{array}{l}\text { Hospitalidade; } \\
\text { Acolhimento; } \\
\text { Turismo; } \\
\text { Literatura } \\
\text { francófona. }\end{array}$ & $\begin{array}{c}\text { Ranaivoson } \\
\text { (2012) }\end{array}$ & $\begin{array}{c}\text { Revista } \\
\text { Hospitalidade }\end{array}$ \\
\hline $\begin{array}{c}* * * * * \\
\text { Resumo_5 }\end{array}$ & $\begin{array}{l}\text { O patrimônio cultural da } \\
\text { cidade de Ilhéus à luz da } \\
\text { literatura de Jorge Amado }\end{array}$ & $\begin{array}{c}\text { Patrimônio } \\
\text { cultural; Mapas } \\
\text { culturais; } \\
\text { Identidade local; } \\
\text { Literatura e } \\
\text { turismo. }\end{array}$ & $\begin{array}{l}\text { Menezes } \\
(2009)\end{array}$ & $\begin{array}{l}\text { Cultur - Revista de } \\
\text { Cultura e Turismo }\end{array}$ \\
\hline $\begin{array}{c}* * * * * \\
\text { Resumo_6 }\end{array}$ & $\begin{array}{l}\text { Turismo e literatura: um } \\
\text { itinerário regiano por } \\
\text { Portalegre }\end{array}$ & $\begin{array}{l}\text { Turismo cultural; } \\
\text { Turismo literário; } \\
\text { Itinerários } \\
\text { literários; } \\
\text { Portalegre; José } \\
\text { Régio }\end{array}$ & $\begin{array}{l}\text { Milheiro e } \\
\text { Pereira } \\
(2014)\end{array}$ & $\begin{array}{l}\text { Revista Turismo \& } \\
\text { Desenvolvimento }\end{array}$ \\
\hline $\begin{array}{c}* * * * * \\
\text { Resumo_7 }\end{array}$ & $\begin{array}{l}\text { Porto Alegre como destino: } \\
\text { Vestígios de iniciativas de } \\
\text { ativação turística a partir da } \\
\text { literatura para viajantes }\end{array}$ & $\begin{array}{l}\text { História do } \\
\text { Turismo; Turismo } \\
\text { Urbano; Guias de } \\
\text { Viagem; Porto } \\
\text { Alegre (RS). }\end{array}$ & $\begin{array}{l}\text { Pimentel e } \\
\text { Castrogiovan } \\
\text { ni }(2018)\end{array}$ & $\begin{array}{l}\text { Revista Anais } \\
\text { Brasileiros de } \\
\text { Estudos } \\
\text { Turísticos/ABET }\end{array}$ \\
\hline $\begin{array}{c}* * * * * \\
\text { Resumo_8 }\end{array}$ & $\begin{array}{c}\text { Viajar e beber. Os Vinhos } \\
\text { Cistercienses de Alcobaça } \\
\text { (Portugal) na Literatura de } \\
\text { Viagens }\end{array}$ & $\begin{array}{l}\text { Alcobaça; Cister; } \\
\text { Viagens; Vinhas; } \\
\text { Vinhos. }\end{array}$ & $\begin{array}{c}\text { Maduro } \\
(2012)\end{array}$ & $\begin{array}{l}\text { ROTUR: Revista } \\
\text { de Ocio y Turismo }\end{array}$ \\
\hline $\begin{array}{c}* * * * * \\
\text { Resumo_9 }\end{array}$ & $\begin{array}{c}\text { A imagem do Rio de Janeiro } \\
\text { no Império e na República } \\
\text { Velha e a nova imagem pós- } \\
\text { grandes eventos esportivos: } \\
\text { Porto Maravilha, literatura e } \\
\text { turismo. }\end{array}$ & $\begin{array}{l}\text { Rio de Janeiro; } \\
\text { Turismo; } \\
\text { Literatura; } \\
\text { Grandes eventos; } \\
\text { Porto Maravilha }\end{array}$ & $\begin{array}{l}\text { Elicher } \\
(2017)\end{array}$ & $\begin{array}{l}\text { Revista Turismo \& } \\
\text { Desenvolvimento }\end{array}$ \\
\hline
\end{tabular}

*Codificação utilizada para elaborar o Corpus Textual que foi analisado a partir do software Iramuteq (versão

0.7 alpha 2).

Fonte: Elaboração própria (2020) a partir de consulta ao Publicações de Turismo (2020) 
Carla Fraga

Maria Jaqueline Elicher

Camila Maria dos Santos Moraes
Geografia, Literatura e Arte, v.2, n.2, p. 90-108, jul./dez.2020

DOI: 10.11606/issn.2594-9632.geoliterart.2020.170156

\section{RESULTADOS E DISCUSSÕES}

A Revista Turismo \& Desenvolvimento apresentou duas publicações (MILHEIRO; PEREIRA, 2014; ELICHER, 2017), o Caderno Virtual de Turismo também (COSTA, 2008; BRUSADIN, 2018) as demais (Revista Hospitalidade, Revista Anais Brasileiros de Estudos Turísticos/ABET, ROTUR: Revista de Ocio y Turismo, Revista Brasileira de Pesquisa em Turismo e Cultur - Revista de Cultura e Turismo) apresentaram uma publicação apenas. Quanto ao ano de publicação, observa-se que o material estudado compreende um período de mais de dez anos, isto é, os trabalhos foram publicados entre 2007 e 2018, sendo 2012 e 2018 os anos mais representativos com dois trabalhos cada um ( Figura 1):

Figura 1 - Ano de Publicação dos estudos ( $\mathrm{n}=9)$

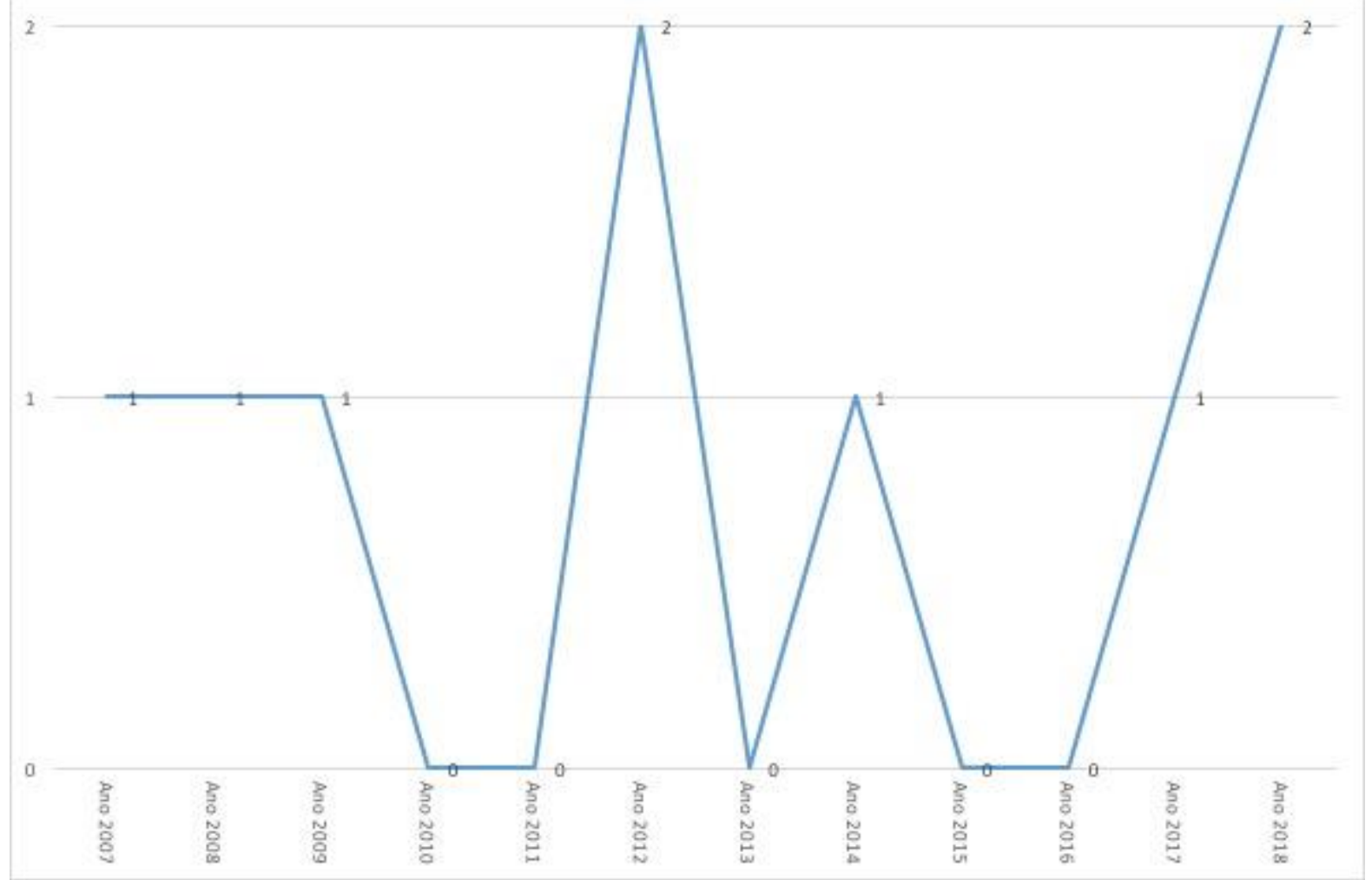


Carla Fraga

Maria Jaqueline Elicher

Camila Maria dos Santos Moraes
Geografia, Literatura e Arte, v.2, n.2, p. 90-108, jul./dez.2020

DOI: 10.11606/issn.2594-9632.geoliterart.2020.170156

Fonte: Elaboração própria (2020) a partir de consulta ao website Publicações de Turismo (2020)

A Figura 2 apresenta a distribuição geográfica, sendo algumas ressalvas para o seguinte: o resumo 1 relaciona-se com a literatura sul-baiana, e cita a cidade de Itabuna na Bahia resumo 4 estão marcados vários pontos de acordo com o dados do artigo (4A à 4G), pois no resumo estava expresso que o seu foco é a literatura francófona produzida nos países coloniais (ver Figura 2):

Figura 2 - Localizações das áreas de interesse dos estudos

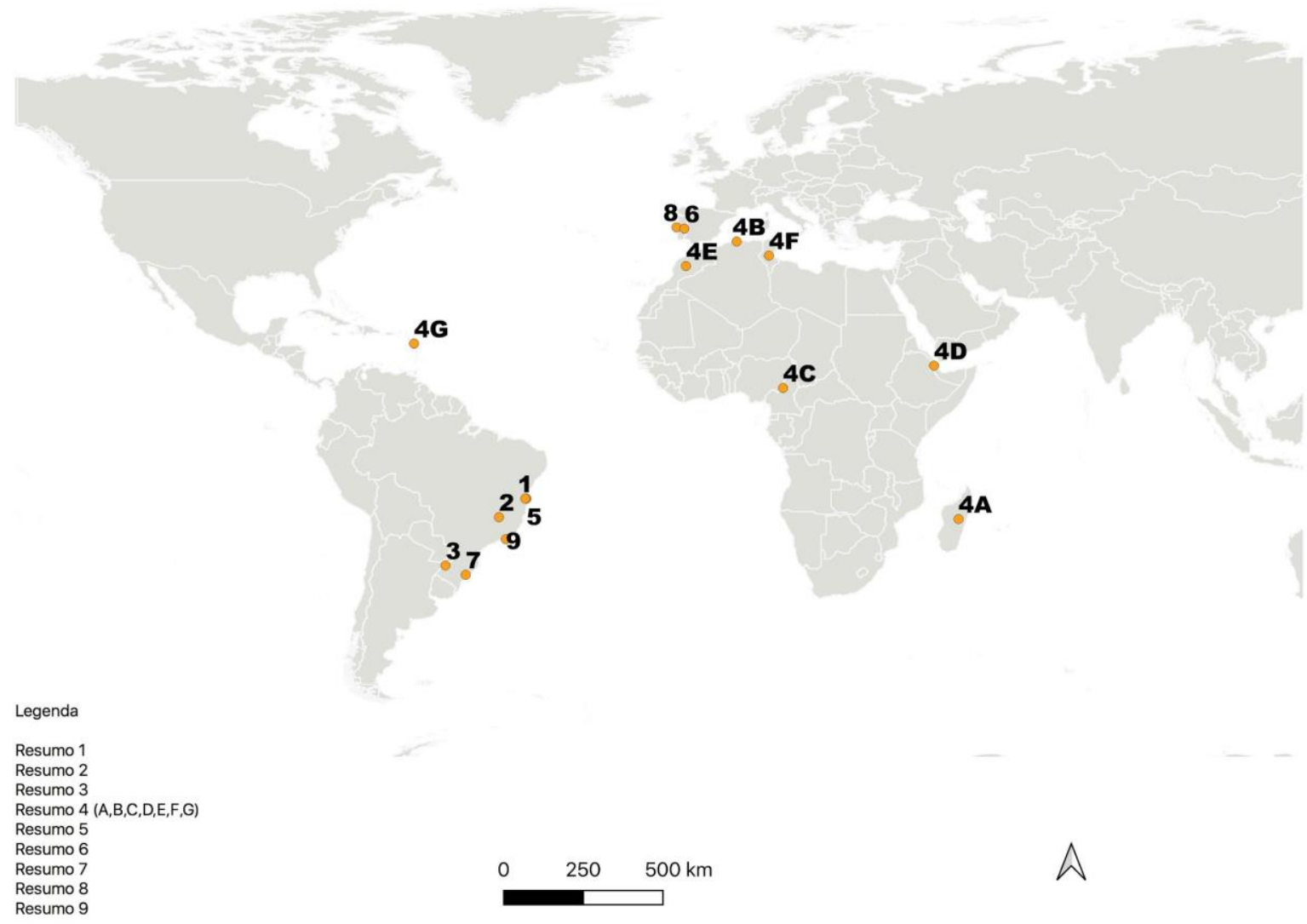

Fonte: Elaboração própria (2020), a partir do uso do software QGis 3.8 Zanzibar

$\mathrm{Na}$ análise textual dos resumos, especificamente na análise da estatística do corpus textual composto por nove resumos foram encontradas 1.299 ocorrências e 517 formas, sendo 
Carla Fraga

Maria Jaqueline Elicher

Camila Maria dos Santos Moraes
Geografia, Literatura e Arte, v.2, n.2, p. 90-108, jul./dez.2020

DOI: 10.11606/issn.2594-9632.geoliterart.2020.170156

371 hapax $^{5}$. Assim, observou-se que muitas formas se repetem poucas vezes e que poucas palavras se repetem muitas vezes no gráfico Zipf (ver Figura 3).

Sendo que a análise estatística do texto é feita a partir da definição de formas ativas (verbos, adjetivos, entre outros) e formas suplementares. No eixo das abcissas os logaritmos apresentam a posição das frequência das palavra por ordem decrescente e no eixo das ordenadas o das frequências das formas (SALVIATI, 2017).

Figura 3 - Análise de Estatística Textual

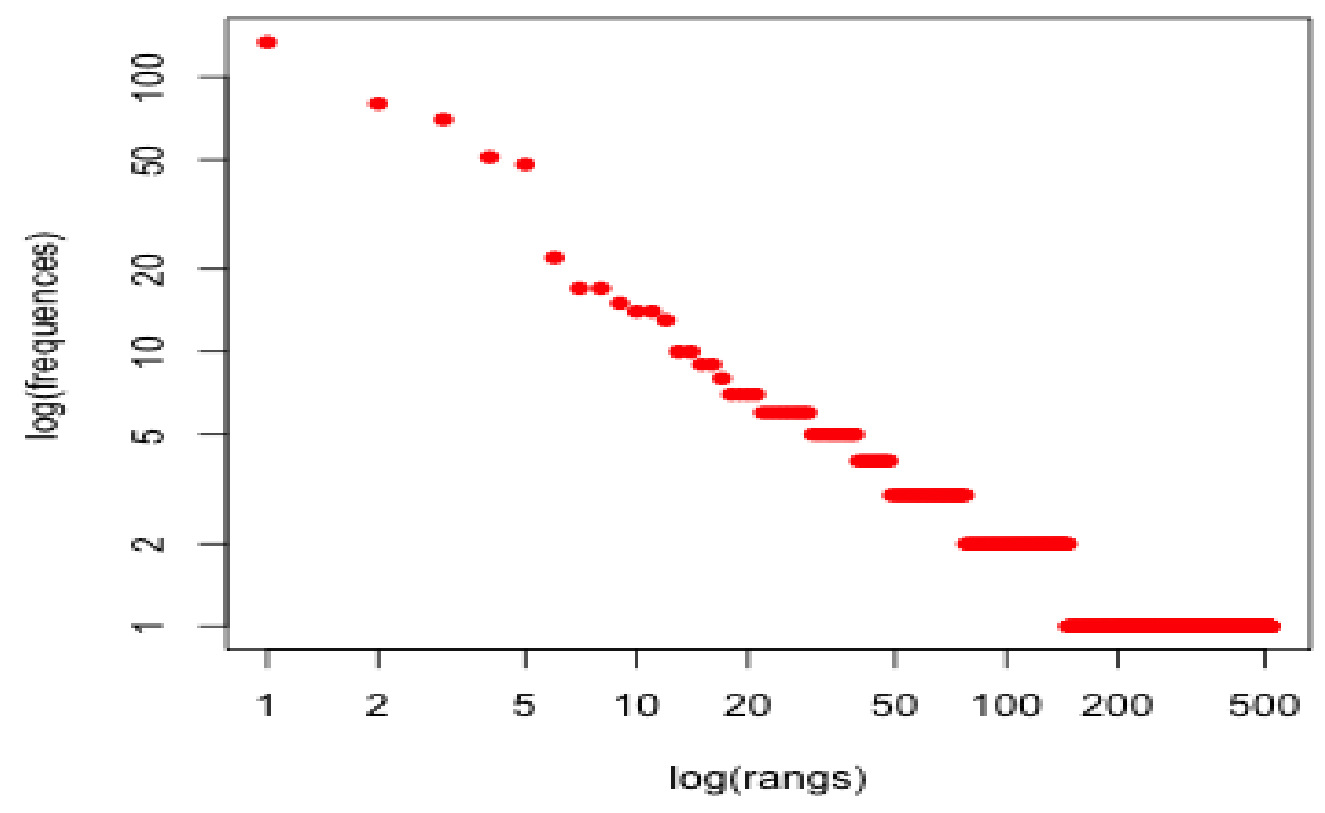

Fonte: Elaboração própria (2020) utilizando o software Iramuteq (versão 0.7 alpha 2)

Já com base nas Teoria dos Grafos, a Análise de Similitude apresenta a ligação entre palavras de um determinado corpus textual (SALVIATI, 2017). Como mencionado, o corpus textual analisado é composto por nove resumos. A Figura 4 é uma apresentação Fruchterman Reingold, que mostra halos de cor para representar comunidades. A partir desta análise é

\footnotetext{
${ }^{5}$ A Hapax são as formas cuja a frequência foi igual a 1, isto é só apareceu uma vez no texto (SALVIATI,
} 2017). 
possível inferir a estrutura de construção do texto, como aponta Salviati (2017), assim os temas de importância, a partir da coocorrência entre as palavras fica evidente. Nesta análise fica evidente que "e" ( $\mathrm{n}=70)$ "como" ( $\mathrm{n}=22)$ são um aspecto chave a ser tratado nesse corpus textual. As palavras "turismo" ( $\mathrm{n}=13)$, "cidade" $(\mathrm{n}=10)$ e "literatura" $(\mathrm{n}=10)$ aparecem na sequência. Logo, é significativo considerar que a ocorrência desta relação entre turismo e literatura em "cidade" também é relevante, portanto, destinos turísticos urbanos são alvo da produção científica analisada, o que contribui para pensar o avanço do conhecimento epistemológico sobre a interface em questão.

Nota-se que há também uma adjetivação da cidade, sendo citada cidade literária, de festivais, festivais literários, de itinerários, itinerários literários, emergindo assim produtos, destinos e serviços que se relacionam com o turismo literário enquanto prática. Como o turismo é marcado por uma prática que antecede uma teoria, quando a teoria expressa aspectos da prática, esta também contribui para que a teoria seja revisitada, e em alguns casos, até revista. Assim, a adjetivação também é um elemento fundamental para uma análise multidisciplinar. Com base no Paradigma das Novas Mobilidades é possível compreender que a literatura se apresenta como um elemento que substância viagens, e portanto, está imersa nas modalidades imaginativas. A Figura 4 apresenta a Análise de Similitude: 
Carla Fraga

Maria Jaqueline Elicher

Camila Maria dos Santos Moraes
Geografia, Literatura e Arte, v.2, n.2, p. 90-108, jul./dez.2020

DOI: 10.11606/issn.2594-9632.geoliterart.2020.170156

Figura 4 - Resultado da Análise de Similitude

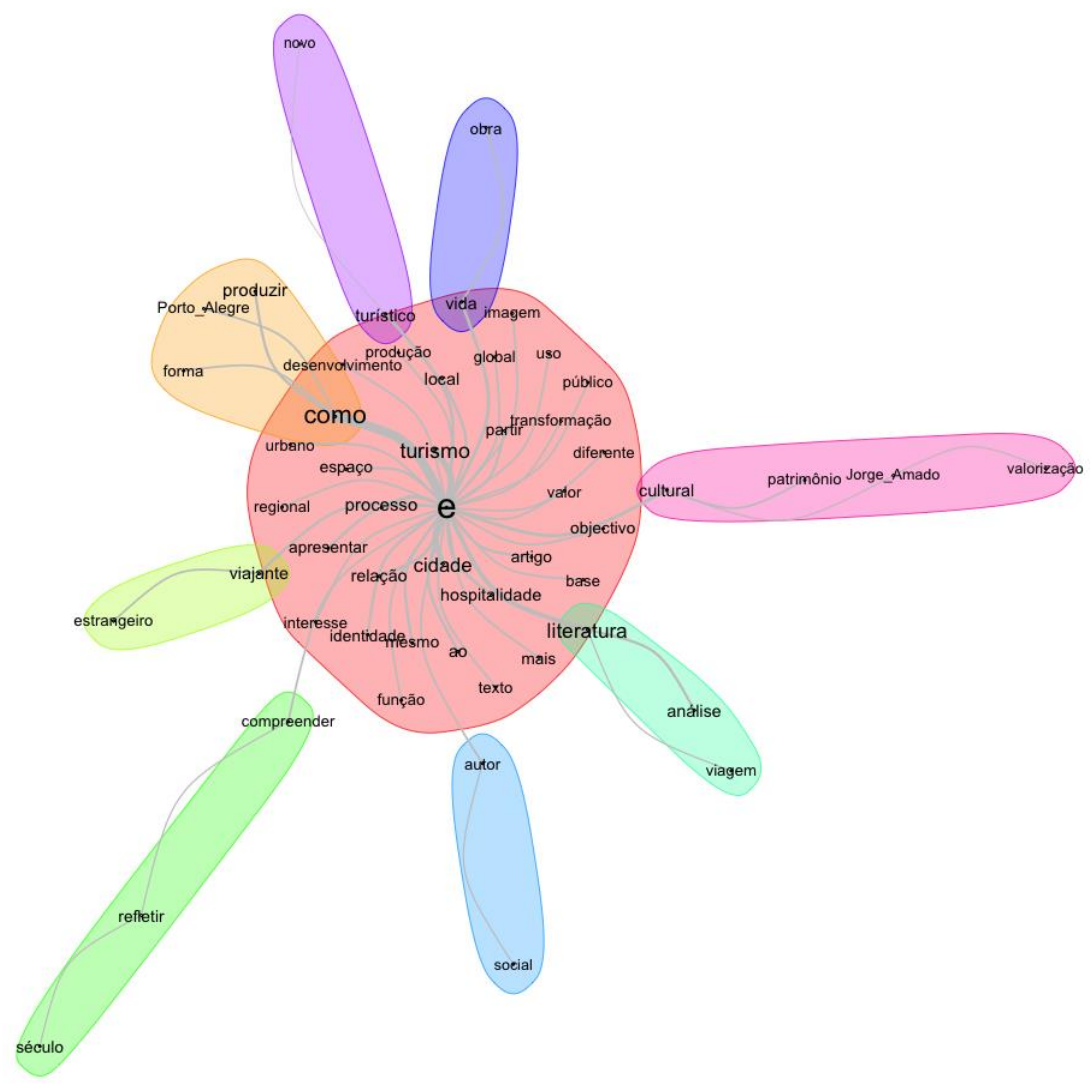

Fonte: Elaboração própria (2020), utilizando o software Iramuteq (versão 0.7 alpha 2)

O conjunto de palavras agrupadas, organizadas e estruturadas formam a Nuvem de Palavra, sendo que os tamanhos das palavras expressam a importância destas, quanto maior e mais central a posição desta, mais importante (de acordo com a frequência que aparecem no texto) para o corpus textual analisado (SALVIATI, 2017) (ver Figura 5) 
Carla Fraga

Maria Jaqueline Elicher

Camila Maria dos Santos Moraes
Geografia, Literatura e Arte, v.2, n.2, p. 90-108, jul./dez.2020

DOI: 10.11606/issn.2594-9632.geoliterart.2020.170156

Figura 5 - Nuvem de Palavras

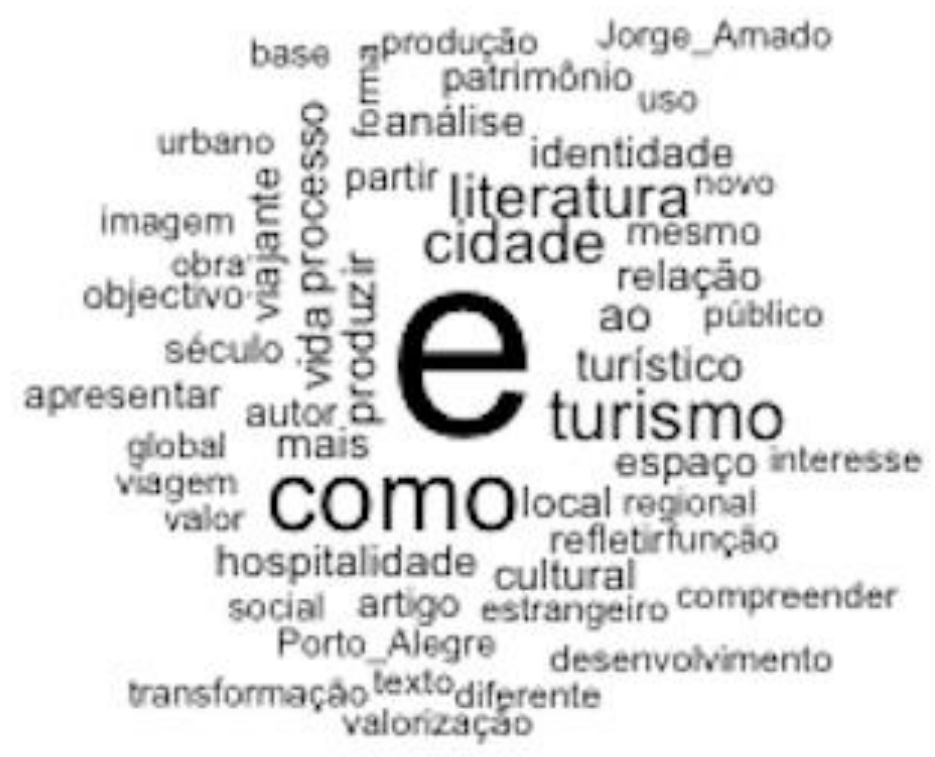

Fonte: Elaboração própria (2020), utilizando o software Iramuteq (versão 0.7 alpha 2)

No avanço epistemológico sobre a relação entre Turismo e Literatura é possível compreender a diferença existente entre as palavras-chave indicadas no Quadro 1 (apenas os resumos 3, 4, 5, 6 e 9 apresentam a palavra "literatura" ou "literário (a;as;os)") e aquelas que são as mais recorrentes nos resumos (ver Figura 5).

Ao se tratar a temática Turismo e Literatura, com uma abordagem multidisciplinar, a luz do Paradigma das Novas Mobilidades (PNM), é possível compreender por exemplo que a valorização a partir da literatura não depende só do fixo, mas também do móvel, a exemplo de Menezes (2009) no Resumo 5 quando foca “(...) imagens ficcionalizadas pelo escritor Jorge Amado sobre a cidade de Ilhéus, no sul da Bahia, podem ser utilizadas para a compreensão e valorização do patrimônio cultural reunido no Quarteirão Jorge Amado" (MENEZES, 2009, s/p.). 
Carla Fraga

Maria Jaqueline Elicher

Camila Maria dos Santos Moraes
Geografia, Literatura e Arte, v.2, n.2, p. 90-108, jul./dez.2020

DOI: 10.11606/issn.2594-9632.geoliterart.2020.170156

A mobilidade das imagens ficcionais para o território é que possibilita a relação entre turismo e literatura. É válido destacar que o móvel aqui é o turista, mas também o livro. Urry (2007) evidencia como a mobilidade de coisas é mais fácil do que a de pessoas, a mobilidade de pessoas é mais cara, encontra mais barreiras (tais como: nacionalidades, vistos, pandemias) e, nesse sentido os livros se movem e podem mobilizar os seus leitores a tornarem-se turistas e se moverem até os lugares. Adicionalmente, cabe explicar que Boden e Molotch, cujo artigo The compulsion of proximity (1994) foi formativo das ideias sobre mobilidades, por mostrar o que mobiliza os movimentos, as viagens, o turismo e, na verdade, por que as pessoas sentem necessidades de se encontrar cara a cara, ou de ir até um lugar" (MORAES, 2016, p. 238).

Quando Maduro (2012, p.149) no Resumo 8 explica a importância das descrições feitas pelos viajantes sobre a vinha e o vinho: "A vinha e o vinho constituem referências significativas nas descrições. São as vinhas da cerca monástica e do relego da Gafa, a grandiosidade da adega e a qualidade dos vinhos que reputam como os melhores da Europa"; também fica evidente que a literatura serve como uma mobilidade imaginativa (que faz o turista viajar para experimentar o vinho) para que as descrições sejam, ao ser lidas na atualidade, uma confirmação para a importância da qualidade dos vinhos.

Costa (2008) no Resumo 1, analisa a produção artesanal de Itabuna na Bahia. Ao fazer isto por meio de entrevista com artesãos, a mobilidade de ideias parece estar presente ligando a memória coletiva e a literatura regional. Desse modo, evocar o Paradigma das Novas Mobilidades (PNM) como uma possibilidade de enlace teórico metodológico para o tratamento da interface entre a memória coletiva e a literatura regional pode ser oportuno para o avanço da relação entre turismo e literatura neste contexto.

O mesmo exemplo pode ser notado no Resumo 7, Pimentel e Castrogiovanni (2018), quando ao investigarem sobre quando Porto Alegre, no Rio Grande do Sul, se torna objeto do 'olhar do turista' (URRY, 2001) os autores escolhem analisar através de 135 documentos da literatura produzida por visitantes. Assim, a ideia sobre Porto Alegre como destino turístico e sua constituição como parte de novos locais em um sistema global de destinos, 
Carla Fraga

Maria Jaqueline Elicher

Camila Maria dos Santos Moraes
Geografia, Literatura e Arte, v.2, n.2, p. 90-108, jul./dez.2020

DOI: 10.11606/issn.2594-9632.geoliterart.2020.170156

como colocam os autores, se dá a partir da mobilidade de ideias, sendo a literatura o fio condutor para a intencionalidade da viagem e olhar sobre o destino como um destino turístico.

\section{CONSIDERAÇÕES FINAIS}

O objetivo deste estudo foi analisar a interface entre turismo e literatura com base na produção científica em Turismo, considerando a visão multidisciplinar a partir do emprego do Paradigma das Novas Mobilidades (PNM). Observou-se que as adjetivações relacionadas ao termo 'literatura' 'literário (a; as;os)' não aparecem nas palavras-chave de todos os resumos e este é um aspecto relevante para se compreender o avanço do conhecimento sobre esta interface entre Turismo e Literatura. Notou-se também que a abordagem multidisciplinar é significativa para o avanço do conhecimento sobre a temática, e isto fica evidente a partir da Análise de Similitude, quando o termo ‘e' assume a centralidade e se liga a 'Turismo' e 'Literatura', bem como a 'Cidades'. Nesse sentido, o Paradigma das Novas Mobilidades (PNM) é um caminho para isto, existindo outros que podem figurar futuros estudos.

Ainda sobre futuros estudos, estes podem ampliar o banco de dados referente ao corpus textual incluindo teses e dissertações, e aplicar A análise Factorial de Correspondência (AFC) para o cruzamento entre vocabulários com base nas formas ativas e o método de Reinert para identificar a classificação. Além disto, a luz do PNM torna-se relevante considerar que o turismo literário (e suas múltiplas formas), está imerso na multidimensionalidade que as mobilidades assumem no contexto contemporâneo.

\section{REFERÊNCIAS}

ANTELMI, Donella; SANTULLI, Francesca. Travellers' memories: the image of places from literature to blog chatter. Pasos Revista de Turismo y Patrimonio Cultural. Universidad de La Laguna (España) e Instituto Universitario da Maia (Portugal). v.10, n.4. Special Issue. pp. 13-24, 2012.

BODEN, Deirdre; MOLOTCH, Harvey. "The compulsion of proximity". In: Roger Friedland, Roger; Boden, Deirdre. NowHere: Space, Time and Modernity. California. University of California Press. pp. 257 - 286. 1994. 
Carla Fraga

Maria Jaqueline Elicher

Camila Maria dos Santos Moraes
Geografia, Literatura e Arte, v.2, n.2, p. 90-108, jul./dez.2020

DOI: 10.11606/issn.2594-9632.geoliterart.2020.170156

BRUM, Ceres, Karam. Turismo, Arqueologia e Literatura: análise antropológica da construção da memória coletiva em São Nicolau, Rio Grande do Sul. Revista Brasileira de Pesquisa em Turismo. Associação Nacional de Pesquisa e Pós-Graduação em Turismo (ANPTUR). v.1. n.1. p.54-83, set. 2007.

BRUSADIN, Leandro, Benedini. Os paradoxos do acolhimento em Minas no século XIX de acordo com a literatura de viagem: hospitalidade e hostilidade. Caderno Virtual de Turismo. Rio de Janeiro. v. 18 n. 3. p.193-207, dez. 2018.

COSTA, Aline de Caldas. Os doces e licores artesanais da literatura sul-baiana e sua relação com o turismo à luz das indústrias criativas. Caderno Virtual de Turismo. Rio de Janeiro. v.8, n.1., 2008.

ELICHER, Maria, Jaqueline. A imagem do Rio de Janeiro no Império e na República Velha e a nova imagem pós-grandes eventos esportivos: Porto Maravilha, literatura e turismo. Revista Turismo \& Desenvolvimento, Aveiro (Portugal). n. 27/28, pp. 899-909, 2017.

FREIRE-MEDEIROS, Bianca.; PINHO, Patrícia de Santana. O turismo num mundo de mobilidades. Apresentação. Plural, Revista do Programa de Pós-graduação em Sociologia da USP, São Paulo, v.23.2, p.5-16, 2016.

MADURO, António, Valério. Viajar e Beber. Os vinhos cistercienses de Alcobaça (Portugal) na literatura de viagens. ROTUR: Revista de Ocio y Turismo. n.5 n.1. pp. 149-160, Coruña, 2012.

MASSEY, Doreen. Pelo espaço: uma nova política da Espacialidade. Tradução: Hilda Pareto Maciel, Rogerio Haesbaert. Rio de Janeiro: Bertrand Brasil, 2008. 312p.

MAVRIC, Misela.; URRY, John. Tourism Studies and The New Mobilities Paradigm In: Jamal, Tazim; Robinson, Mike. The SAGE Handbook of Tourism Studies. London: SAGE, p. 645-657, 2009.

MENEZES, Juliana, Santos. O patrimônio cultural da cidade de Ilhéus à luz da literatura de Jorge Amado. Cultur - Revista de Cultura e Turismo, Ilhéus - BA (Brasil), ano3 n.3., jun. 2009.

MILHEIRO, Eva.; PEREIRA, Maria, Eugénia. Turismo e literatura: um itinerário regiano por Portalegre. Revista Turismo \& Desenvolvimento. Aveiro (Portugal). v.1. n.21/22. pp. 8190, 2014.

MORAES, Camila Maria dos Santos. Favelas Ecológicas: passado, presente e futuro do turismo em favelas. Tese de Doutorado defendida no Programa de Pós-Graduação em História, Política e Bens Culturais. Rio de Janeiro: FGV / CPDOC-RJ, 2017. 
Carla Fraga

Maria Jaqueline Elicher

Camila Maria dos Santos Moraes
Geografia, Literatura e Arte, v.2, n.2, p. 90-108, jul./dez.2020

DOI: 10.11606/issn.2594-9632.geoliterart.2020.170156

MORAES, Camila Maria dos Santos. Entrevista com Monika Buscher. Trama: Indústria Criativa em Revista. Dossiê: Mobilidades e Cotidianos. Marechal Cândido Rondon - PR (Brasil), ano 1, v.1, p. 235-257, janeiro a julho de 2016.

ONFRAY, Michel. Teoria da Viagem - poética da geografia. Porto Alegre: L\&PM, 2009. PIMENTEL, Maurício, Ragagnin; CASTROGIOVANNI, Antônio, Carlos. Porto Alegre como destino: Vestígios de iniciativas de ativação turística a partir da literatura para viajantes. Revista Anais Brasileiros de Estudos Turísticos. Juiz de Fora - Minas Gerais (Brasil). v.8 n.1 Jan./Abr. pp. 53-71, 2018.

$\begin{array}{llll}\text { PUBLICAÇÕES } & \text { DE } & \text { TURISMO. } & \text { Disponível }\end{array}$ <http://www.each.usp.br/turismo/publicacoesdeturismo/> Acessado em 14 abr.2020.

QUINTEIRO, Silvia. Os lugares da literatura: Mapas e rotas literárias. Cultur. Ilhéus - BA (Brasil), ano 13, n.2, p. 4-13, jun/2019.

QUINTEIRO, Silvia.; BALEIRO, Rita. (2014). Estudos em Literatura e Turismo: Conceitos Fundamentais. Lisboa: Universidade de Lisboa. $1^{\circ}$ edição, dez. 2017.

RANAIVOSON, Dominique. Acolher, explicar, desvelar: até onde me apresentar ao outro? Transparência e opacidade nas literaturas francófonas. Revista Hospitalidade. São Paulo - SP (Brasil). v. IX n.2. pp. 140-154, jul-dez./2012.

SALVIATI, Maria, Elisabeth. Manual do Aplicativo Iramuteq (versão 0.7 Alpha 2 e $R$ Versão 3.2.3). Planaltina, março de $2017 . \quad$ Disponível em <http://iramuteq.org/documentation/fichiers/manual-do-aplicativo-iramuteq-par-mariaelisabeth-salviati> Acesso em 21 jul. 2019.

SANTOS, Milton. Técnica, Espaço, Tempo. Globalização e meio técnico-científico informacional. São Paulo: Editora Hucitec, 1997.

SIMÕES, Maria de Lourdes Netto. Identidade cultural e turismo: a literatura como agenciadora de trânsitos e possível elemento de sustentabilidade. In: CRUZ; CAMARGO (orgs). Turismo Cultural - Estratégias, Sustentabilidade e Tendências. Ilhéus: Editus, 2009. p. 49-68. Disponível em < http://www.uesc.br/icer/artigos/aidentidadecultural.pdf> Acesso em 5 ago. 2020.

SHELLER, Mimi; URRY, John. The new mobilities paradigm. Environment and Planning A. University of British Columbia (Canada) v. 38, n. 2, p. 207 - 226, 2006.

SHELLER, Mimi. Tourism Mobilities: places to play, places in play. New York: Routledge, 2004. 
Carla Fraga

Maria Jaqueline Elicher

Camila Maria dos Santos Moraes
Geografia, Literatura e Arte, v.2, n.2, p. 90-108, jul./dez.2020

DOI: 10.11606/issn.2594-9632.geoliterart.2020.170156

TEJERO, Cristina Martínez. Turismo, literatura e gentrificação: Os festivais e cidades literárias perante as consequências do fenómeno turístico. Revista Turismo \& Desenvolvimento. Aveiro (Portugal) v.2. n.27/28. pp. 367-369, 2017.

URRY, John. Mobilities. Cambridge: Polity. 2007.

URRY, John. O Olhar do Turista. São Paulo: SENAC, 2001.

URRY, John. Sociology beyond Societies. London; New York: Routledge. 2000.

Recebido em 27/05/2020.

Aceito em 08/09/2020.

Publicado em 07/11/2020. 